\title{
“RECORDAR É PODER": ESTRATÉGIAS DE UMA MEMÓRIA FAMILIAR DISTINTA EM CENTENÁRIAS FAZENDAS DO CARIRI PARAIBANO ${ }^{1}$
}

\author{
Valdênio Freitas Meneses ${ }^{2}$
}

\begin{abstract}
RESUMO: O artigo propõe analisar estratégias que envolvem usos da memória familiar associada a centenárias fazendas na região do Cariri Paraibano. Utilizando do exemplo das fazendas Capitão-Mor e Pitombas da família Fernandes Batista é possível analisar como, em um contexto de transformações sociais recentes, parte de uma elite rural sob ameaça de desprestígio transformou patrimônios materiais e simbólicos. Esse tema é próximo a um debate no campo de estudos das reconversões sociais, estratégias de mudança e permanência sobre capitais econômicos, culturais e simbólicos. São analisadas duas estratégias da família Fernandes Batista: uma parte dos livros de memória que destacam a escolarização de duas gerações da família. Já outra estratégia trata da conservação do patrimônio material tornando as fazendas - outrora espaços de produção econômica em museus e arquivos, ou seja, locais de memória e culto e nostalgia de uma ordem social pecuarista passada.
\end{abstract}

Palavras-chave: elite; família, reconversões sociais; memória; Cariri paraibano

\section{LANDOWNER ELITES AND STRATEGIES OF FAMILIAR MEMORY AND SOCIAL DISTINCTION ( CARIRI-PARAIBA)}

\begin{abstract}
The article analyzes how a family makes strategies using memories about the social condition of agrarian and cattle breeder elites at the region of Cariri (Paraíba, Northeast Brazil). This kind of rural elites is threatened with social decline because of social transformations in the last two decades in Brazil. The study proposes an approach to social reconversions and how this group tries to change the economic, cultural and symbolic capitals. The main objective is to analyze two narratives about the memory and the past of the farm. The first refers to the process of schooling of the members of a generation of the family. The second is the conservation of architectural heritage, making farm family museums to exhibit objects and documents. This strategy attempts to construct an idyllic view of one social order that no longer exists.
\end{abstract}

Key-words: elite; family; social reconversions; memory, Cariri paraibano.

\section{INTRODUÇÃO}

Em 1987 avançava uma crise de preços e também da praga do Bicudo nas lavouras de algodão do Cariri paraibano. Nesse mesmo ano faleceu Malaquias Batista Feitosa, conhecido

\footnotetext{
${ }^{1}$ Esse artigo é resultado de um recorte da tese Saudade e rusticidade: reconversões sociais e convivência com as secas entre elites pecuaristas do Cariri paraibano apresentada no Programa de Pós Graduação de Ciências Sociais em Desenvolvimento, Agricultura e Sociedade (CPDA/UFRRJ). A tese, vencedora do Prêmio CAPES 2019 na área Sociologia, pode ser consultada na íntegra através do seguinte link:

https://sucupira.capes.gov.br/sucupira/public/consultas/coleta/trabalhoConclusao/viewTrabalhoConclusao.jsf?po pup $=$ true \&id trabalho $=6584492$

${ }^{2}$ Professor no departamento de Direito da Faculdade Maurício de Nassau, Campina Grande - PB. Doutor em Ciências Sociais pelo CPDA/UFRRJ. Contato: valdeniofmeneses@ gmail.com
} 
Revista NEP - Núcleo de Estudos Paranaenses, Curitiba, v. 5, n. 2, dez. 2019

também como "Batista Malaquias", proprietário e "patrão" das fazendas Capitão-Mor, Pitombas e Santa Clara - área rural de São Sebastião do Umbuzeiro-PB. O corpo do Sr. Malaquias foi levado de um hospital, em Recife, para ser velado nas fazendas em que ele criou seus filhos junto com a esposa Sebastiana "Sinhá" Fernandes cultivando também um círculo de aliados políticos, amigos e compadres. Em um texto publicado no livro de homenagem aos 100 anos de Malaquias - Papai Histórias \& Estórias (2005) - um dos filhos, Laurentino Fernandes, registra a mesma mensagem que escreveu durante um voo que veio de Brasília para João Pessoa na Paraíba e que foi lida no dia do velório:

\footnotetext{
"Oitenta e dois anos marcaram a tua presença entre nós. Viver foi projeto enquanto vida. Vaqueiro foi tua profissão, honra maior (...) Te amamos te admiramos, te respeitamos e te seguimos. Sábio mestre. Teu Saber cristalizou nossas vidas. Patrimônio maior que deixaste para os filhos. Pai Batista, Ramada, Pitombas, CapitãoMor, terras onde nasceste, cresceste e morreste, serão eternos símbolos de tua vida. (...) Homem de opinião e de defesa dos princípios da sociedade. A morte leva um esposo, um pai, um avô, um bisavô, um irmão, um sogro, um amigo e um vaqueiro, um patrão e um político e deixa esposa, filhos, netos, bisnetos, genros, noras e amigos, vaqueiros e companheiros, uma saudade tão grande, um espaço vazio e uma vontade de um dia te encontrar. (FERNANDES, 2005, p. 77)
}

Em 1988, aniversário de um ano da morte, os filhos e a viúva Sebastiana "Sinhá" se reúnem no alpendre da fazenda Pitombas. Essa reunião é narrada no capítulo "Mãe, e o semiárido" no livro Mãe Sinhá: memórias e lições, homenagem a Sebastiana Fernandes organizado por Batista Filho (2014). Segundo o relato, esse foi o momento dos Fernandes Batista, em consulta a amigos e aliados políticos, reunirem-se e tratarem da divisão de heranças e funções entre os irmãos, a fim de administrar do "vermelho" as contas nas fazendas cada vez mais esvaziadas de trabalhadores e moradores. A partir dessa reunião foi definido um dos principais investimentos feitos até hoje, principalmente no espaço da fazenda Capitão-Mor: na memória da família, seja em confraternizações, lançamentos de livros até a criação de um museu particular - que veio a ser inaugurado em 2014 - para expor objetos e documentos escritos ligados a um passado das genealogias da família Fernandes Batista e parentes.

O recorte desses trechos que narram desde a morte de Malaquias Batista até uma reunião tida como decisiva para o futuro da família Fernandes Batista, indica alguns processos que tem acontecido junto a famílias detentoras de centenárias fazendas da região do Cariri paraibano - 
ao menos daquelas propriedades que "sobreviveram" a uma crise da economia algodãopecuária, que entrou em desmonte a partir do final do século XX. Utilizando do exemplo dos Fernandes Batista é possível analisar como, em um contexto de transformações sociais do interior do Cariri e do semiárido nordestino nos últimos vinte anos, uma família de elite mobiliza e transforma sobre patrimônios materiais e simbólicos, ou seja, seus recursos materiais, classificações e visões de mundo. Esse tema é próximo a um debate no campo de estudos das reconversões sociais, estratégias de mudança e permanência sobre capitais econômicos, culturais, simbólicos. Sob inspiração da sociologia de Pierre Bourdieu, foi construído um campo de pesquisas sociológicas e antropológicas sobre elites e suas reconversões - exemplos disso, no caso da nobreza da França autores como Monique de Saint Martin (1995, 2014) e sobre as elites agrárias brasileiras, Afrânio Garcia Jr. (1989, 2007).

No caso dos Fernandes Batista - como será analisado adiante - há um selo de uma herança agrária e pecuarista recebido por uma geração da família que se viu desafiada por uma nova condição social de ameaças de desclassificação a sua distinção de origem: a dissolução, intensificada entre as décadas de 1960-1990, de um conjunto de relações sociais que dinamizava a economia do algodão e pecuária das fazendas e uma lógica social subordinava através de uma diversidade de relações de trabalho - "; "trabalho alugado"; " cambão" a "partilha" da colheita ou do rebanho como no "quarto dos vaqueiros" - famílias de sitiantes e trabalhadores rurais que possuíam pouca ou nenhuma terra. Em síntese um sistema de trabalho que tinha pouco ou nenhum vínculo de assalariamento ${ }^{3}$ e que, além de uma sujeição estritamente econômica e material era uma relação de dominação circundada de uma moralidade de favores e reciprocidades.

A dissolução dessa lógica de relações sociais de trabalho, moradia e economia que combinava terra, pecuária bovina e exportação de algodão é aqui estudada estritamente sob o ponto de vista expresso nos livros de memória ligados à familia Fernandes Batista - a trilogia

\footnotetext{
3 No Brasil rural de boa parte do século XX, a produção exportadora e as hierarquias entre proprietários e trabalhadores rurais foram legitimadas por vínculos sociais com diversos nomes: "moradia", "agregados", "o trabalho alugado", "cambão", "terça" ou "sujeição", dentre outros que variavam no tempo, local, e tipo de atividade nas grandes propriedades. Em termos materiais, a "troca" entre proprietários da terra e trabalhadores agregados podia ser feita através de múltiplas funções na fazenda - como agricultores em épocas de colheita e plantio, vaqueiros, empregados da casa sede, jagunços etc. - e em variadas formas de pagamentos que combinavam a "doação" de um terreno para moradia , a "partilha" da colheita com dias de trabalho alternados "na terra do patrão" e dias de trabalho em roçado próprio, ou apartação de animais do rebanho, no caso do "quarto dos vaqueiros" (ANDRADE, 2011, p. 205). Em termos simbólicos, os agregados se "sujeitavam" aos fazendeiros dentro de prestações e compromissos regidos por códigos de conduta e hierarquia que, no geral, pouco incluíam contratos jurídicos ou salariais - se baseavam em reciprocidades desiguais de bens, compadrio, parentesco, amizade e até ameaças com uso de violência física e intimidade sexual (RIBEIRO, 2011, p. 398).
} 
Retrato Escrito (1993, 2000, 2005), de Maria José Amaral França, e os livros Papai: Estórias e Historias (2005) e Mãe Sinhá Memórias e lições (2014), organizados por Malaquias Batista Filho e irmãos. Também utilizo de dados de entrevistas, fotografias e registros feitos em pesquisa de campo realizada nas fazendas da família Fernandes Batista entre 2015 e 2017. A partir daqui, o artigo está estruturado nas seguintes partes: 1) Um breve diálogo empírico e teórico para falar da relação de uma elite nordestina da pecuária com as transformações recentes no Cariri e de como esse caso pode ser debatido e provocar teses que renovaram uma sociologia do poder e das elites na França além de trabalhos recentes que tem retomado a agenda de pesquisas sobre as redes de poder e parentesco no Brasil. Na segunda parte, inicio com a relação da "história" do sobrenome da família Fernandes Batista com o jogo de poder das oligarquias paraibanas no inicio do século XX. Após esse comentário passo para o estudo das "narrativas de escolarização" que falam das estratégias de "saída e retorno" a fazenda que pelos quais as gerações dos Fernandes Batista adquiriram não apenas competências universitárias mas também disposições, gostos e interesses na escrita de livros de memória e genealogia. $\mathrm{Na}$ terceira parte trato das estratégias no patrimônio das fazendas Capitão-Mor, Pitombas e Santa Clara: de como o espaço físico dessas propriedades - outrora voltado para atividades econômicas agropecuárias - se torna local privilegiado de culto aos antepassados, da realização de encontros e reencontros com os parentes, eventos podem acompanhar missas, apresentações musicais, lançamento de livros e um museu particular, inaugurado em 2014, com arquivos de objetos e documentos.

\section{1. “RECORDAR É PODER": ELITE E MEMÓRIA}

Neste artigo, quando menciono o termo elite me refiro a frações de grandes proprietários de terra e pecuaristas do Cariri da Paraíba, um grupo social que tem enraizamento histórico em todo semiárido nordestino. Por mais que haja afinidades desses pecuaristas do Nordeste com a defesa da grande propriedade da terra que marca certo ethos empresarial rural do agronegócio, do cinturão do Centro Oeste ao Norte do Brasil (BRUNO, 2009), ou com os grandes pecuaristas brasileiros do gado Zebu de circuitos, como de Uberaba-MG (LEAL, 2016), é importante demarcar algumas especificidades desse grupo social, que se autoproclamam como autênticos "sertanejos e nordestinos". Tem-se uma relação não apenas afetiva, mas política, com um conjunto de narrativas de ocupação territorial do sertão "na pata do gado", ou seja, de extrair uma distinção social ao afirmar descender da chamada "civilização do couro", termo que circulou entre memorialistas, folcloristas e escritores, seguindo clássicos como Capistrano de 
Abreu [1904] (1954). Para os pecuaristas, essa expressão, mais que um conceito historiográfico, evoca símbolos de poder e o prestígio de pertencer à linhagem colonial de um "Outro Nordeste" pecuário, rústico e de costas para os canaviais do litoral (MENEZES, [1937] 1970). Ciente de que essas teses são questionadas em recentes trabalhos historiográficos ${ }^{4}$ interessa aqui ver como pessoas que pertencem a essa elite usam e reforça essas narrativas como amuletos para tentar manter certa distinção.

Outro fator bastante citado são dinâmicas da grande propriedade pecuarista do Nordeste em uma lógica de poder mais ampla que, pela coerção do voto ou de redes de pessoas e compromissos, ampliou a influência da grande fazenda pecuarista ao nível das decisões no Estado brasileiro em quase todo século XX. Essa gramática de dominação política de parlamentares recrutados da elite proprietária do interior da então chamada região "Norte" tem uma historicidade específica junto à dramatização pública do fenômeno das secas. É essa relação que historiadores, sob diferentes epistemologias, problematizaram: como membros de uma elite, recrutados das origens pecuaristas e proprietárias rurais, atuaram sob várias frentes no tema das secas, e firmaram uma forte e durável demarcação e política no imaginário nacional do Brasil. Tomando como recorte o estado da Paraíba na República Velha, o trabalho de Linda Lewin (1993) analisa o poderio das parentelas de famílias proprietárias que se dividiam entre as oligarquias dos Machado e dos Leal, e que dinamizavam alianças entre as classes médias urbanas e os proprietários rurais do sertão, vinculados ao consórcio pecuária/algodão, até a Revolução de 1930, na Paraíba. A nível federal, foi nesse mesmo mapa político que foram feitos conchavos e dramatizações de deputados que pediam salvação ao "Norte sofrido das secas" para controlar a construção das linhas dos trens da Great Western Company, no boom exportador algodoeiro na primeira metade do século XX (ARANHA, 2011).

Nos últimos trinta anos essa elite tem sofrido certos desgastes que vão de fatores econômicos das fazendas chegando a atingir emblemas de prestígio social. As elites pecuaristas do Cariri paraibano vão sofrer um desgaste mais intenso de seus emblemas sociais distintivos na década de transição entre os séculos XX e XXI. Como apontam Buanain e Garcia (2013, p.218), esse é o período em que são consolidadas junto aos pobres algumas das garantias de cidadania previstas na Constituição de 1988. O combate à pobreza rural é feito em várias vertentes: do crédito para agricultura familiar (PRONAF), junto a políticas ambientais,

\footnotetext{
${ }^{4}$ Vide os trabalhos sobre abastecimento na colônia ( Linhares,Teixeira, 1997) bem como o de Aldo Nunes (2016) sobre a ocupação colonial do atual semiárido em dinâmicas agrícolas e de comércio, ou seja longe dessa visão linear da pecuária/povoamento/fazendas dos sertões coloniais
} 
investimentos em mudanças na estrutura agrária e demográfica, até novos referenciais de ação local, como os Territórios da Cidadania. Nesse período, no Cariri paraibano, se seguiu uma tendência de uma certa fragmentação fundiária e criação de assentamentos sendo muitos deles via projetos de financiamento e crédito. Se até meados da década de $1980^{5}$ pesquisas feitas pela UFPB registravam um circuito das grandes fazendas do consórcio da produção algodoeira para alimentação da pecuária principalmente bovina (DUQUE, 1985, p.171). Nos anos 1990, o casario de muitas antigas fazendas já estava abandonada e em ruínas: esvaziadas pela saída dos moradores, seja pela migração ou certo avanço de direitos de assalariamento/previdência, ou pela falta de competência ou dificuldades dos herdeiros para gerir atividades rurais cada vez menos lucrativas, as propriedades foram colocadas à venda no mercado privado ou através de projetos governamentais de aquisição de terras.

Ainda em termos de fatores econômicos outro sinal do declínio de uma rede de dependências do "patrão" fazendeiro sofrerá retalhos está no avanço direitos trabalhistas, aposentadoria e previdência para os trabalhadores rurais. Junto a isso, tem a presença intensificada, na década de 2000-2010, de uma rede de políticas públicas para crédito, transferência de renda e programas de combate à fome, como Bolsa Família e PAA, aumento real do salário mínimo, dentre outras melhoras no poder aquisitivo dos mais pobres (BACELAR, 2010). A junção desses fatores é apontada como uma das razões possíveis para a melhora no IDH da região Nordeste com padrões de diminuição da atividade agropecuária nos PIBs municipais, aumento dos recursos de transferência de renda e aposentadorias, e a crescente formalização de empregos na administração pública trazem melhoras para os índices de renda, pobreza e desigualdade - o que, no caso do Cariri paraibano, aconteceu em uma proporção três vezes maior em relação ao total dos municípios brasileiros. (FAVARETO ET AL, 2011, p. 19).

Também há perdas significativas dessa elite em variáveis não estritamente econômicas: padrões de gênero, identidade, trajetórias de vida, perspectivas de trabalho, padrões de consumo e gostos musicais, principalmente nas novas gerações de jovens que transitam no eixo rural e urbano dos municípios, no interior do Nordeste. Entre final do século XX e início do XXI fica ainda mais nítido como os sertanejos são, antes de tudo, seres sociais em mudança: há um lento desmanche no monopólio de estereótipos - identificados com as elites pecuaristas - que enquadram a visão do Nordeste apenas como o "sertão" rústico, isolado, fechado nas tradições

\footnotetext{
${ }^{5}$ Ocasionalmente entre a década de 1940-1970 houve momentos de integração com outras atividades como a extração do caroá; fábricas de fibra de agave; venda de mercadorias em barracões; carvão mineral e um movimento de políticas públicas e financiamento de crédito ao plantio da algaroba (CUNHA; GOMES, 2012).
} 
em que circulariam seres masculinos e encouraçados, como cangaceiros, vaqueiros, retirantes, cantadores de viola, jagunços, coronéis e padres. Essas imagens se tornarão ainda mais anacrônicas diante de mudanças significativas que anunciam recentes trabalhos acadêmicos. São os filhos de vaqueiros e agricultores que trabalharam toda vida nas fazendas, traçando uma trajetória diferente da dos pais, sendo empregados no crescente comércio local das cidades e que, assim, "abdicam do chapéu de couro presenteado pelo pai para usarem bonés" (MOREIRA, 2014, p. 227).

É nesse contexto de risco de desclassificação de um prestígio social atacado sob várias frentes que foram traçadas as estratégias simbólicas ligados a memória e a terra dos Fernandes Batista. O registro desses movimentos está nas fontes que utilizei na pesquisa que deu origem a esse artigo: os livros de Laurentino Fernandes Batista; Idalina Fernandes Batista e Malaquias Batista (2005) e Batista Filho (2014) e Amaral França (1993; 2004,2005). Guardadas as especificidades citadas, a construção da memória e genealogia dessas elites apontam alguns padrões já registrados em várias pesquisas sobre o tema da memória e familia. Desde o ato em si de registrar em livro as memórias ${ }^{6}$ dos antepassados da família até a justificativa desinteressada de terem uma circulação restrita aos parentes e amigos, os livros são formas socialmente úteis para perpetuar e reafirmar um prestígio, que é o principal critério de seletividade das lembranças, junto a apresentação do sentimento de uma nostalgia no sentido de afirmar a posteriori um passado bucólico , relembrar toda " uma era de ouro que ficou no pretérito" (LE WITA, 1985, p. 7). A "linha editorial” de memórias de elite também pode operar com outros recursos. Sobre a socialização dos herdeiros ricos na elite francesa, Pinçon e Pinçon Charlot (2002) chamam atenção para a construção da imagem dos palacetes da família como espaços privilegiados, berços da memória e culto aos antepassados de uma linhagem - a fazenda Capitão-Mor e Pitombas no caso do memorial dos Fernandes Batista cumpre esse papel . Também há o registro de fotografias e genealogias visando firmar um passado glorioso, um capital distinto e político, como aponta os trabalhos de Leticia Cañedo $(1998,2002)$ nas famílias políticas de Minas Gerais , por fim, a produção de perfis biográficos, ou seja, a fabricação seletiva de um "senso comum da vida apresentada como se fosse um deslocamento linear, todo coerente e orientado" (BOURDIEU, 2006, p.184).

\footnotetext{
${ }^{6}$ A memória coletiva como tema sociológico tem seu clássico na interpretação durkheimniana de Maurice Halbwachs. (1990)
} 
Revista NEP - Núcleo de Estudos Paranaenses, Curitiba, v. 5, n. 2, dez. 2019

Este artigo também dialoga com um esforço recente de pesquisadores de diferentes regiões do Brasil que atualizaram uma sociologia da família, parentesco e politica no Brasil. Tema clássico da nossa formação sociológica, passou por alguns momentos de certo ostracismo ( ou forçada "regionalização" - mas vem sendo revigorado pelas pesquisas que envolvem redes de capital político e familiar que transita de espaços eleitorais até o judiciário de estados que tem diferentes composições políticas como o Paraná ( COSTA DE OLIVEIRA et al 2017); na Paraíba ( MONTEIRO, 2017). Através dessas pesquisas pode-se afirmar que o tema da família e poder não é desatualizado, nem trata de resquícios de tradição ou de um passado prestes a desaparecer no Brasil. Tampouco é um fenômeno restrito ao poder local de uma região: família e poder é um elo que remete a um fenômeno sociológico bastante explicativo de dinâmicas centrais e bastante atuais na política e sociedade brasileira.

No cruzamento dessa literatura sociológica citada acima e na análise dos livros de memórias dos Fernandes Batista podem ser feitas algumas reflexões sobre como uma família detentora de médias e grandes fazendas do semiárido nordestino teceu suas estratégias de reconversões sociais - especificamente trato menos das relações matrimoniais e eleitorais da família e invisto o olhar sociológico nas estratégias ligadas ao poder e a memória familiar ligada à grande propriedade da terra . É nessa metamorfose de capitais econômicos - posse da terra em memórias e símbolos distintos que é tema central das perguntas que movem o debate desse artigo. Como os descendentes de uma elite dramatizam os processos de transformação sobre suas famílias e suas fazendas? Será que os "filhos" das elites assentadas em um "nome de família" e na memória de "ciclos" do algodão e pecuária interpretam que houve um desmonte da moradia em termos de "crises" ou "declínio" de si mesmos enquanto grupo distinto? Como é produzida e reelaborada a autoimagem distinta de elite diante de novas situações sociais? A partir de quais argumentos e "seletividades" nostálgicas os descendentes de Malaquias Batista e Sebastiana "Sinhá" Fernandes, constroem uma narrativa biográfica dos pais, avós e também suas próprias memórias? Como os autores dos livros narram as suas próprias trajetórias de escolarização em instituições secundaristas e universidades de Pernambuco e Paraíba? Em que essa escolarização influi na própria reprodução social de uma distinção e prestígio do nome Fernandes Batista em relação a outras famílias da mesma região?

Nos tópicos seguintes, essas questões serão debatidas após de uma breve apresentação de uma história política duas estratégias da família Fernandes Batista: uma estritamente narrativa que parte dos livros de memória dos Fernandes Batista destacam a escolarização dos "nascidos" na Capitão-Mor. Já outra estratégia parte dos livros mas se objetiva e na conservação do 
patrimônio material tornando as fazendas - outrora espaços de produção econômica - em um local de culto à memória e também de nostalgia de uma ordem social pecuarista passada.

\section{0: A HONRA EM UMA TRANSFUSÃO DE SANGUE: BREVE HISTÓRIA DE FAMILIA E PODER NO CARIRI DA PARAIBA}

A Fazenda Capitão-Mor, junto com Pitombas e Santa Clara, formam um círculo propriedades dos Fernandes Batista, localizado na área do município de São Sebastião do Umbuzeiro-PB, entre os limites com o município de Zabelê-PB, São João do Tigre-PB e com o município de Sertânia-PE. Juntas, as três propriedades somam 2927 hectares. A Capitão-Mor é a maior propriedade abrangendo cerca de 1260 hectares, divididos em duas localidades: Capitão- Mor (980ha) e Capitão-Mor de Cima (280ha). Pitombas possui 337 hectares e a Santa Clara 70 hectares.

Mapa 1: Município de São Sebastião do Umbuzeiro- PB e Fazendas Capitão-Mor, Pitombas, Santa clara

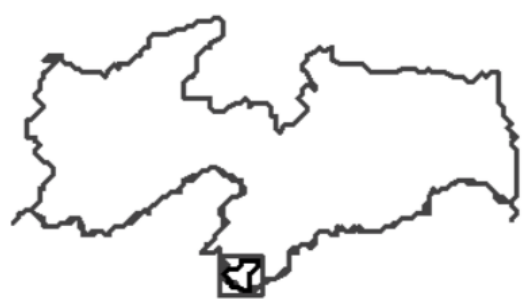


Revista NEP - Núcleo de Estudos Paranaenses, Curitiba, v. 5, n. 2, dez. 2019

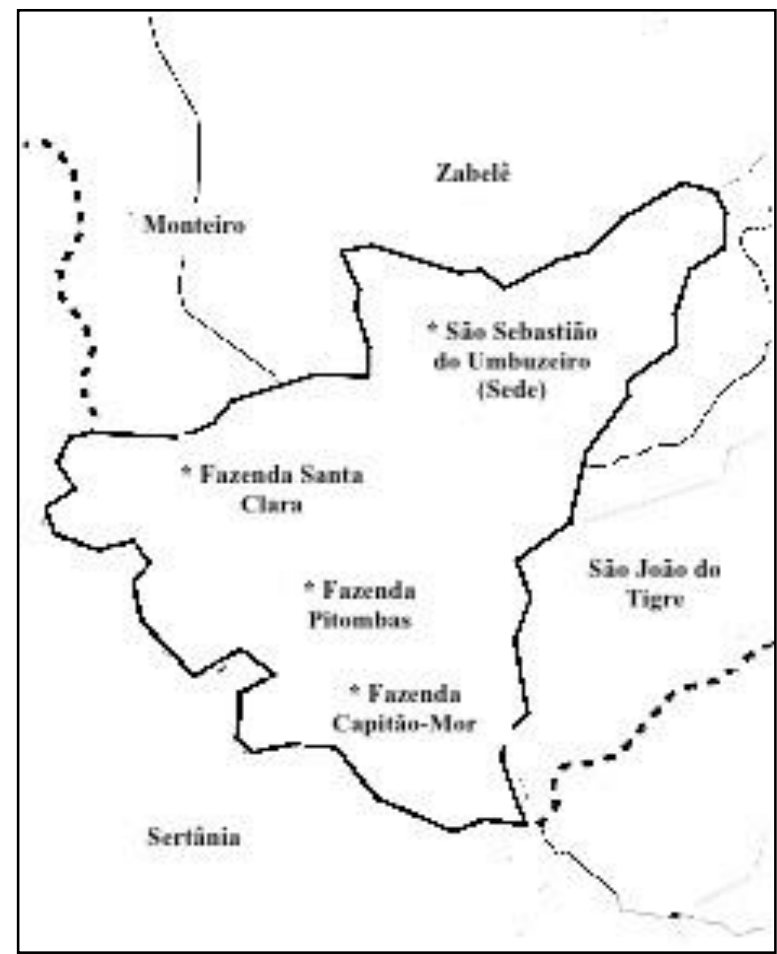

Fonte: Mapa Municipal Estatístico (IBGE)

Na história dessas fazendas e da "origem” do sobrenome Fernandes Batista é possível notar alianças e rupturas intrafamiliares, um pequeno corte no tecido de uma rede de política e parentesco de oligarquias traçada entre final do século XIX e meados do XX na Paraíba e que influenciou nas dinâmicas fundiárias e eleitorais na região dos Cariris Velhos. Essa história também menciona episódios de violência, honra e assassinatos.

Um primeiro momento de disputa oligárquica e de "sangue" que envolveu os ancestrais da família Fernandes Batista foram conflitos armados nos primeiros trinta anos do Século XX. Primeiro a chamada “ Guerra de 12" protagonizada pelo juiz Augusto Santa Cruz na cidade de Alagoa de Monteiro (1912) ( NUNES FILHO, 1995). A investida armada de Santa Cruz contra forças politicas representadas pelo Coronel Nilo Feitosa e outras famílias mostram algumas das tensões que iriam explodir em 1930 quando as oligarquias do sertão entraram em conflito com a nascente elite urbana da capital (então chamada Parahyba do Norte). Além de marcar uma mudança no balanço de poder oligárquico, a “ Revolução de 30" marca a memória familiar de elites paraibanas pelo elemento trágico: os assassinatos por honra do então governador João Pessoa e do deputado João Suassuna, os dois primos e "apadrinhados" políticos do expresidente Epitácio Pessoa que representavam os conflitos entre sertão/litoral. 
Revista NEP - Núcleo de Estudos Paranaenses, Curitiba, v. 5, n. 2, dez. 2019

ISSN: 2447-5548

Nesse cenário conturbado da primeira metade do século XX a famílias Maciel e Feitosa - da qual descende Malaquias Batista, "patriarca" da Capitão-Mor - tiveram suas rivalidades e "questões" acentuadas, principalmente intrafamiliares. Esse acirramento ficou acentuado após o casamento entre Malaquias Batista com Sebastiana Fernandes. Após o matrimônio ele passa Malaquias passa a apoiar, em 1940, o sogro José Fernandes, contra os parentes partidários de Cel. Nilo Feitosa, em uma política local que ainda ecoavam as disputas de 1912 e 1930.

Uma série de assassinatos de primos Feitosa entre fazendas Pitombas e Juazeiro, do médico e político João Feitosa, por questões de animais e terras, iria iniciar um então "racha" interno na família. Na década de 1950, parte dela manteve firme apoio ao filho de Nilo, o deputado João Feitosa Ventura, da UDN, enquanto que a outra, capitaneada por Malaquias Batista, ficou com o Partido Social Democrático (PSD). Essa rivalidade familiar e partidária demarcada em apelidos populares entre "Marmiteiros" (PSD) contra os "Bocas pretas" (UDN) (FERNANDES BATISTA, 2005) - foi tão intensa que fez com que Malaquias justificasse negar a repassar o sobrenome Feitosa em todos os seus filhos, deixando apenas o Fernandes Batista que marca aliança com a esposa Sebastiana. Um momento em que Malaquias, no final da vida, teve de fazer uma transfusão de sangue em um hospital de João Pessoa -PB é exemplar de como operam os significados de sangue e honra que originaram o sobrenome Fernandes Batista:

\footnotetext{
- Como está seu Batista? Perguntou o médico.

- Bem, muito bem doutor, nunca estive tão bem na vida.

- Por que, seu Batista?

-Doutor, acho que perdi todo o sangue Feitosa que corria em minhas veias. Recebi doação de sangue de um batalhão de soldados do $15^{\circ}$ Regimento de Infantaria. Fiz questão de excluir da lista de doadores qualquer Feitosa. Tenho sangue de Ferreira, de Gomes, de Silva, de Bezerra, de Oliveira, de Rafael etc. E tal. Não tenho mais sangue Feitosa, Dr. João Feitosa. Estou livre da maldição! (FERNANDES BATISTA ET AL, 2005, p. 52)
}

Essa situação de Malaquias Batista mostra como o conflito faz flutuar fronteiras familiares e como elas podem ser representadas. É esse ponto que levanta Ana Claúdia Marques (2002, p. 328), em pesquisa sobre intrigas e "questões" familiares no sertão pernambucano, que o sangue é um estoque físico mas simbólico sobre o qual "famílias traçam suas fronteiras que jamais são definitivas". E foi por essa dimensão de sangue, politica e honra que construído o sobrenome Fernandes Batista e parte de uma "geografia afetiva" das fazendas Capitão-Mor e Pitombas que seria trabalhada pelas gerações posteriores da família que ingressaram nos espaços 
escolares e universitários das capitais da Paraíba e Pernambuco. Esse é o tema do próximo tópico.

\title{
2.1: “ OS FILHOS SÃO OS BANCOS DE MANUTENÇÃO DA PROPRIEDADE” : A ESCOLARIZAÇÃO DOS DOUTORES DA CAPITÃO-MOR
}

A narrativa do livro "Mãe Sinhá" (2014) consagra a figura materna como principal incentivadora moral na formação escolar dos filhos: a frase "dá-se um jeito" é tida como uma filosofia de vida de Sebastiana Fernandes, que fez uma escola primária dentro da fazenda para os filhos aprenderem a ler e escrever.

\begin{abstract}
Como estudar, se não tinha escola nem pública nem privada, nos nossos grotões e cercanias? Dá-se um jeito. E o jeito foi construir uma escola, num salão anexo à casa grande de Capitão-Mor, com porta de entrada, duas janelas de iluminação e ventilação, uns bancos escolares, uma mesa grande para as sabatinas, uma lousa e a temida palmatória. Contratou uma professora: Maria Antonieta de Albuquerque, ou apenas D. Etinha, então com 16 anos de idade, sem diploma de professora, sem curso de pedagogia, como formalmente seria a exigência. Foi o jeito que se deu para nossa iniciação nos estudos e para os meninos dos sítios e fazendas vizinhos: Pitombas, Estrela D’Alva, União, Boa Sorte. Uma escola privada com cobertura pública (BATISTA FILHO, 2014, p. 28).
\end{abstract}

Um outro nome lembrado pelos livros e entrevistas dos Fernandes Batista é o do fazendeiro e engenheiro André Bezerra Rego Barros, amigo de Malaquias Batista, "patriarca" da fazenda vizinha Estrela D’Alva - que atualmente é área de um assentamento com mesmo nome ${ }^{7}$. O "Dr. André" é tido como um incentivador para escolarização dos filhos de Malaquias e "Sinhá". Através da aplicação de testes e tabuadas, o "Dr. André” comenta com "Sinhá" que os seus "meninos tem futuro", o que faz com que, no fim da década de 1950, ela comece a enviar os filhos para estudar em colégios de Pesqueira-PE, à época um intenso centro urbano e industrial na região agreste de Pernambuco. Os meninos iriam para o Colégio Cristo Rei e as meninas para o ginásio religioso das Lourdinas (BATISTA FILHO, 2014, p. 29). Segundo o relato dos filhos, o "jeito" para pagar os colégios de Pesqueira foi o esforço conjunto da "fibra de nervos, músculos, resistência, tolerância e superação da mãe, junto ao ativo do agave a das

\footnotetext{
${ }^{7}$ No fim da década de 1980 para os anos 1990, a fazenda Estrela D’alva passou por um processo de desapropriação para tornar-se área de assentamento do mesmo nome. Para uma referência sobre antigas fazendas de gado, que se tornaram assentamentos através do Programa Nacional de Crédito Fundiário na região do Cariri paraibano, ver a dissertação de Miriam Silva (2012).
} 
fábricas de fibras do Caroá, além de pecuária combinada com algodão de safras entre 1945 e 1955 (BATISTA FILHO, 2014, p. 29).

Em entrevista ${ }^{8}$ com o Sr. Malaquias Batista Filho, quando peço para que fale sobre o momento em que saiu da Capitão-Mor para estudar (por volta do final da década de 1950), ele destaca que, diferente da mãe, o pai teve uma resistência ao fato dos filhos saírem, pois era muito centrado na propriedade e temia que se distanciassem da política local do município de São Sebastião do Umbuzeiro, recém emancipado de Monteiro (1958). Contudo, o Sr. Batista Filho afirma que os primeiros sinais de uma crise no algodão fizeram com que o pai mudasse de ideia e se voltasse para o estudo dos filhos:

\begin{abstract}
Malaquias Batista: Papai dizia propriedade não é pra dar lucro (...) propriedade era qualquer coisa que você fazia por tradição (...) claro que isso dava lucro no tempo de João José do meu bisavô (...) mas depois que mantendo essa regra do jogo no passado começou a dar prejuízo (...) ele [Papai] apelava para os filhos dizia bem (...) os filhos são os bancos de manutenção da propriedade.
\end{abstract}

A relação entre o declínio da produção algodoeira e o capital investido na "saída", dos filhos, da fazenda dá indicação do manejo e transmissão de valores em situação de risco de desclassificação, ou seja do temor do grupo perder condições de reprodução social de um status. O período de 1960-1980, em que todos os filhos de Malaquias e Sinhá ou estão em conclusão ou já são formados em cursos universitários, é visto como momento que acentuam dificuldades pelas secas e que marcam o "fim dos ciclos" de alguns dos produtos que faziam circular a economia local: extrativismo de caroá e agave e, principalmente, os preços do algodão com a praga do bicudo, e a concorrência das fibras sintéticas (BATISTA FILHO, 2014, p.30). Não é apenas uma crise na renda econômica dos proprietários, mas um mal-estar pela dissolução e falta de recursos para manter uma ordem social, sentida principalmente na saudade, junto a um senso de "tarefa a ser cumprida" pelos herdeiros de Malaquias e Sinhá, em trânsito entre as férias na fazenda e os períodos escolares em João Pessoa ou Recife. Alguns traços desse sentimento são perceptíveis na descrição da sensação de sair do limite de uma vida "no campo", como, por exemplo, nas primeiras falas de uma entrevista feita no alpendre da casa sede da Capitão-Mor, quando solicito que o Sr. Laurentino faça uma fala autobiográfica:

Valdênio: O senhor pode falar da sua vida?

Laurentino: Eu nasci aqui nessa casa [Capitão-Mor], em janeiro de 1950, no município de São Sebastião de Umbuzeiro. Tive toda minha infância aqui, até hoje. Onze anos de idade, eu não tinha saído daqui, não conhecia além de São Sebastião de

\footnotetext{
8 Todas as entrevistas citadas no artigo podem ser acessadas na íntegra através do seguinte link < https://drive.google.com/open?id=1vApk-_QmMelBcohVhsHtoKD7NGxZrvM8 >
} 
Revista NEP - Núcleo de Estudos Paranaenses, Curitiba, v. 5, n. 2, dez. 2019 Dossiê Oligarquias do Nordeste no Brasil

ISSN: 2447-5548

Umbuzeiro e Sertânia. Meus limites ficavam exatamente aqui até os 11 anos de idade. Fui alfabetizado aqui na escola Santa Teresinha, que está aqui na nossa frente, com uma professora que morava aqui em casa [...] Convivendo com bode, com a cabra, com o cachorro e com o porco. Minha passagem de infância foi normal para uma criança do meio do campo, não teve nada além da criança do meio do campo. Certamente o ciclo... nós estávamos mais ou menos no auge, ou melhor, nós estávamos no início do fim do ciclo de algodão, mas ele ainda era muito determinante aqui. Se vivia muito dele, que era algodão, boi e bode. Essas coisas tinham uma relação muito forte, que você cultivava o algodão, quando tirava o algodão, botava boi e depois botava bode pra reaproveitar tudo. Era um ciclo bem interessante e era algodão mocó de fibra longa.

Valdênio: Qual sua sensação de sair daqui [Capitão-Mor] e ir estudar fora?

Laurentino: Pois é, evidentemente que eu não entendia muito o que estava acontecendo, mas eu estava indo porque estavam mandando e tinha que ir cumprir a tarefa. Evidente que eu morria de saudade daqui. A saudade era uma coisa maluca que nos meus dias lá de angústia em João Pessoa e a angústia demorou até uns 15 ou 16 anos, depois eu comecei a compreender o outro cenário, mas a vontade era voltar, sempre era de voltar. Aí cumpri o primário todo, fui fazer o ginásio e fiquei determinado que eu faria agronomia. Eu sou o segundo agrônomo do município de São Sebastião do Umbuzeiro

As falas dos Srs. Malaquias Filho e Laurentino mostram a visão da crise segundo cada um dos "porta vozes" dos dois grupos que dividem hierarquias entre os filhos de Malaquias Batista e Sebastiana Fernandes: de um lado, os mais velhos, nascidos na Fazenda Pitombas (antes de 1945), e os que nasceram na Fazenda Capitão-Mor após a mudança que os pais fizeram da moradia na fazenda. No quadro abaixo, demarco as trajetórias biográficas e escolares dos onze filhos vivos do casal Batista Malaquias e Sinhá : 
Tabela 1 : Local de nascimento e formação escolar dos filhos de Malaquias Batista e Sebastiana Fernandes

\begin{tabular}{|c|c|c|}
\hline NOME & $\begin{array}{l}\text { FAZENDA } \\
\text { EM QUE } \\
\text { NASCEU }\end{array}$ & FORMAÇÃO ESCOLAR E PROFISSIONAL \\
\hline Malaquias Batista Filho & \multirow{7}{*}{$\begin{array}{l}\text { Pitombas } \\
\text { (1934- } \\
\text { 1945) }\end{array}$} & $\begin{array}{l}\text { Fez curso secundário no Colégio Cristo-Rei em Pesqueira-PE. Formado em medicina e nutrição pela Universidade de São } \\
\text { Paulo (USP); professor aposentado da UFPE; Diretor do Instituto Materno Infantil de Pernambuco (IMIP); Consultor da } \\
\text { ONU e UNICEF em missões internacionais. Mora em Recife-PE. }\end{array}$ \\
\hline Eudésia Fernandes Batista & & Fez o curso secundário nas Lourdinas, em Pesqueira-PE. Comerciante e reside Sumé. \\
\hline José Fernandes Neto & & $\begin{array}{l}\text { Fez curso secundário no Colégio Cristo-Rei em Pesqueira-PE. Formado em economia pela UFPB é empresário de } \\
\text { comunicação (Jornal Correio da Paraíba); Foi Secretário de Indústria e Comércio da Paraíba (1994-1998). Mora em João } \\
\text { Pessoa- PB. }\end{array}$ \\
\hline Elza Fernandes Batista & & $\begin{array}{l}\text { Fez o curso secundário nas Lourdinas, em Pesqueira-PE. Atualmente é empresária do setor de comércio turístico e reside } \\
\text { em João Pessoa. }\end{array}$ \\
\hline Quitéria Fernandes Batista & & Advogada, formada na UFPB, trabalha no fórum da cidade de Sumé-PB. \\
\hline Idalina Fernandes Batista & & Fez o curso secundário nas Lourdinas, em Pesqueira-PE, e agronomia na UFPB de Areia-PB. Atualmente mora em Brasília. \\
\hline Maria do Socorro Fernandes Batista & & Professora no campus da UFPB, em Areia-PB. \\
\hline Laurentino Fernandes Batista & \multirow{4}{*}{$\begin{array}{l}\text { Capitão- } \\
\text { Mor } \\
(1945- \\
\text { 1965) }\end{array}$} & $\begin{array}{l}\text { Fez o curso secundário em João Pessoa e o curso de agronomia na UFPB de Areia-PB. Foi secretário Adjunto de Ciência } \\
\text { e Tecnologia de Brasilia. Primeiro Reitor da Universidade de Tocantins; Foi presidente da associação de avicultores do } \\
\text { Centro Oeste. Atualmente é empresário do ramo de carne suína nas fazendas Nova Capitão-Mor e Nova Pitombas em } \\
\text { Goiás. }\end{array}$ \\
\hline Antônio Fernandes Batista & & $\begin{array}{l}\text { Fez curso secundário no Colégio Cristo-Rei em Pesqueira-PE. Formado em odontologia (UFPB), atualmente é empresário } \\
\text { e fazendeiro em Porto Velho, Rondônia ( RR). }\end{array}$ \\
\hline Maria da Conceição Fernandes Batista & & $\begin{array}{l}\text { Fez o curso secundário nas Lourdinas, em Pesqueira-PE. Enfermeira formada pela UFPB; Trabalha no hospital de São } \\
\text { Sebastião do Umbuzeiro, onde também foi Secretária de Saúde. Reside na fazenda Capitão-Mor, em São Sebastião do } \\
\text { Umbuzeiro (PB). }\end{array}$ \\
\hline Maria de Fátima Fernandes Batista & & $\begin{array}{l}\text { Fez o curso secundário nas Lourdinas, em Pesqueira-PE. Advogada formada na UFPB; Trabalha no fórum da cidade de } \\
\text { Monteiro-PB e foi prefeita da cidade de São Sebastião do Umbuzeiro (1997-2000). }\end{array}$ \\
\hline
\end{tabular}

Elaborado a partir de Amaral França (1993, p. 18) ;Batista Filho et al (2005, p. 32-33) e Batista Filho (2014, p.27) 


\subsection{FAZENDAS CAPITÃO-MOR, SANTA CLARA E PITOMBAS: LOCAIS DE CULTO DA MEMÓRIA DA FAMÍLIA FERNANDES BATISTA}

"O mundo começa aqui". Assim está gravado uma placa talhada por Idalina Fernandes em um muro da casa grande da Fazenda Capitão-Mor, local de vários encontros entre parentes e amigos da família. Batista Filho (2004, p. 75) aponta que esses encontros não seriam possíveis se não fosse a iniciativa da sua prima Maria José Amaral França, a “Zezé”, de escrever a primeira genealogia de seus parentes.

As publicações de Zezé, os Retratos Escritos, são a principal fonte para a pesquisa genealógica que posteriormente seriam complementadas e atualizadas nos livros dos Fernandes Batista. No Retrato Escrito I, lançando em 1993, Amaral França conclui um trabalho que envolveu o registro de memórias, a busca por parentes por carta e telefone nos estados de Pernambuco e Paraíba. O referencial para escrita do livro era a história de um capitão chamado João José da Silva, neto de portugueses que, na metade do século XIX, "fugiu” da fazenda Mochila, pertencente a família Silva Souza; que atualmente fica próxima a cidade de Garanhuns-PE e ocupou terras na região chamada de "Cariris Velhos" na Paraíba. Segundo Amaral França (1993, p. 15). João José fundou a fazenda Santa Clara, além de estabelecer um duplo casamento com as irmãs Joana e Iaiá, da família Fernandes da fazenda Capitão-Mor.

È através da memória dos deslocamentos do "patriarca” João José que Amaral França (1993) elabora genealogias que "resgatam" um elo ancestral comum entre a sua família, os Santana, os Silva Souza; e os Fernandes Batista. O livro Retrato Escrito II é elaborado a partir da inclusão de novas informações nas genealogias junto a um conjunto de cartas e poemas, alguns deles escritos com agradecimentos das pessoas da família Fernandes Batista. O livro II, por exemplo, inicia com apresentação de José Fernandes Neto (2003, p. 11) que compara o livro de Zezé com uma chuva que "encheu um rio de memórias que estava secando" na sua família. Irmão de José Fernandes, Malaquias Batista também agradece a Zezé: “ antes tínhamos um só nome de batismo com dois ou três sobrenomes,(...) agora temos uma resenha de 8 gerações, uma memória de 200 anos, cobrindo 40\% da cronologia histórica do brasil ( BATISTA FILHO, 2004, p. 75) 
No livro que fecha a trilogia, Zezé Amaral agradece as cartas e poemas dos parentes e relembra os encontros em que foi convidada pelos filhos de Malaquias Batista e Sinhá Fernandes. Cruzando as informações dos livros de Amaral França (2005) com os livros de autoria dos Fernandes Batista pode ser percebida a predileção pelas fazendas como local para os encontros "oficiais" entre os parentes :

TABELA 2: ENCONTROS ENTRE AS FAMÍLIAS SANTANA, FERNANDES BATISTA, SILVA SOUZA

\begin{tabular}{|c|c|c|}
\hline DATA & LOCAL & MOTIVO \\
\hline Maio de 1983 & $\begin{array}{l}\text { Fazenda Capitão-Mor e } \\
\text { Pitombas, próximo ao } \\
\text { município de São } \\
\text { Sebastião do Umbuzeiro - } \\
\text { PB }\end{array}$ & $\begin{array}{l}\text { Missa campal e festa em comemoração aos } \\
50 \text { anos de casamento de Malaquias Batista } \\
\text { e Sebastiana Fernandes }\end{array}$ \\
\hline 15 de julho de 1989 & $\begin{array}{l}\text { Casa de Inácio Souza no } \\
\text { município de São } \\
\text { Sebastião do Umbuzeiro }\end{array}$ & $\begin{array}{l}\text { Primeiro encontro da família "idealizado" } \\
\text { por Inácio Souza ( ex-prefeito de São } \\
\text { Sebastião do Umbuzeiro) }\end{array}$ \\
\hline 7 de agosto de 1993 & $\begin{array}{c}\text { Fazenda Lagoa Rasa, em } \\
\text { Pesqueira-PE }\end{array}$ & $\begin{array}{l}\text { Encontro promovido por Zezé de Amaral } \\
\text { França, na sua fazenda }\end{array}$ \\
\hline 20 de janeiro de 2001 & $\begin{array}{l}\text { Fazenda Capitão-Mor e } \\
\text { Pitombas }\end{array}$ & $\begin{array}{l}\text { Inauguração de uma rua chamada Florêncio } \\
\text { Souza Lima na cidade de São Sebastião do } \\
\text { Umbuzeiro } \\
\text { - Aposição de uma placa na Fazenda } \\
\text { Pitombas } \\
\text { - Inauguração de uma casa restaurada em } \\
\text { Capitão-Mor }\end{array}$ \\
\hline 6 de julho de 2002 & $\begin{array}{l}\text { Fazenda Lagoa Rasa, em } \\
\text { Pesqueira- PE }\end{array}$ & $\begin{array}{l}\text { Segundo encontro provomido por Zezé de } \\
\text { Amaral França }\end{array}$ \\
\hline Maio de 2005 & Fazenda Capitão-Mor & $\begin{array}{l}\text { Lançamento do livro Papai: estórias e } \\
\text { Histórias. } \\
\text { - Aposição de uma placa em homenagem a } \\
\text { Malaquias Batista }\end{array}$ \\
\hline Dezembro de 2014 & Fazenda Capitão-Mor & $\begin{array}{l}\text { Lançamento do livro Mãe Sinhá: memórias } \\
\text { e lições } \\
\text { Criação de um museu da família. }\end{array}$ \\
\hline
\end{tabular}

Elaborada a partir de observações de placas no alpendre da Capitão-Mor junto com dados dos livros de Amaral França ( 2004, p. 128) ; Batista Filho (2014, p. 105-109)

Outro forte investimento memorial é na conservação de objetos, documentos e da próprio conjunto arquitetônico da casa sede da Capitão-Mor. Segundo Batista Filho (2014, p.24) e Laurentino Fernandes (2005, p.77), para que a Capitão-Mor fosse uma "hospedaria", ponto de passagem e repouso no fluxo de comerciantes, vaqueiros e amigos 
Revista NEP - Núcleo de Estudos Paranaenses, Curitiba, v. 5, n. 2, dez. 2019

de Malaquias Batista e Sebastiana Fernandes, que faziam a rota a cavalo ou automóvel entre pequenos comércios, barracões nas fazendas e as grandes feiras de cidades como Sertânia, Pesqueira, Arcoverde (antiga Rio Branco), em Pernambuco, e Monteiro, na Paraíba. Esse fluxo de pessoas permitia a circulação de notícias sobre a política, sobre a ação de bandos de cangaceiros e a possibilidade de negociar mercadorias na fazenda (BATISTA FILHO, 2005, p. 25).

Foto 1: Casa sede da fazenda Capitão-Mor

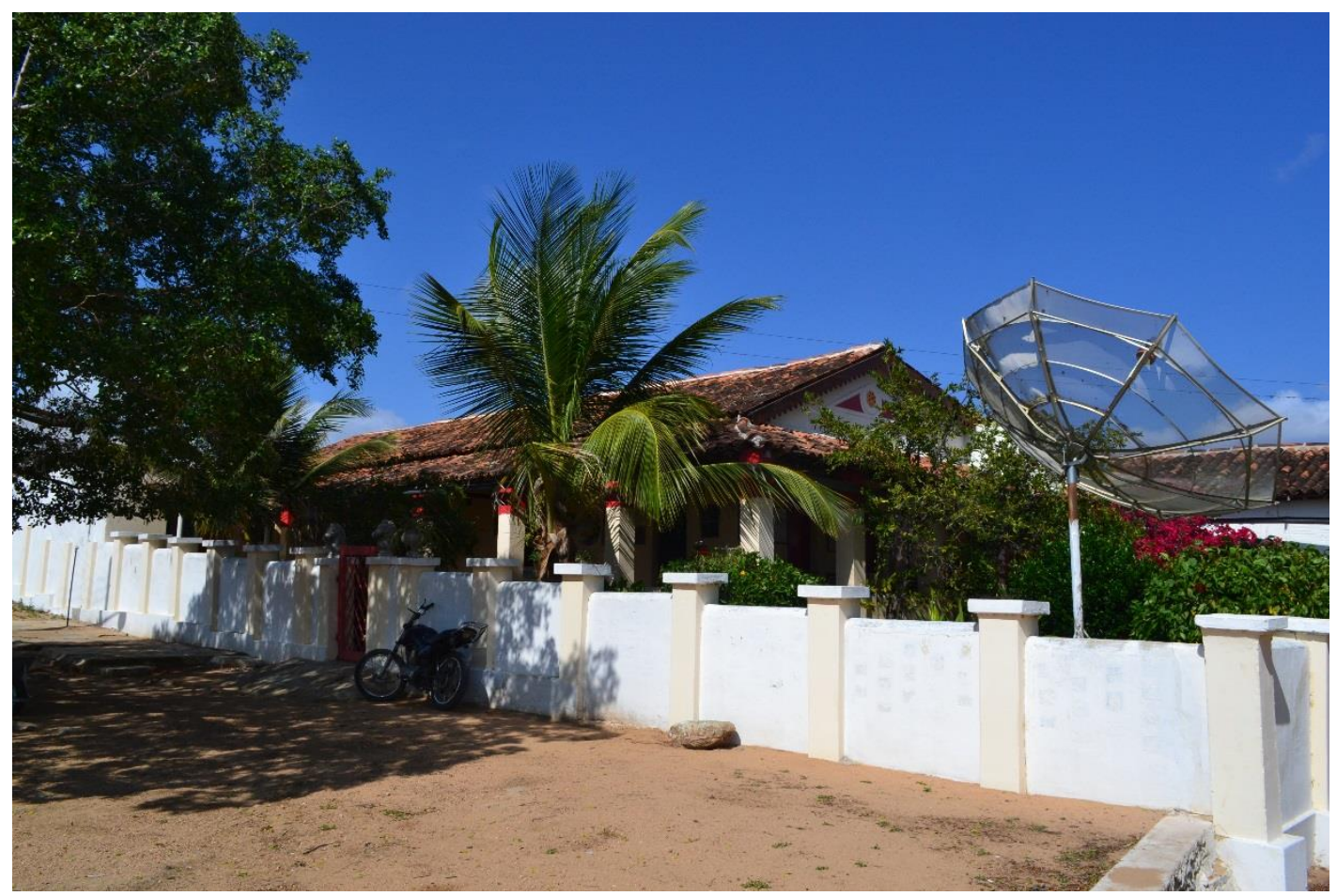

Registro feito por Valdênio Meneses (2017)

As explicações para a disposição de objetos e cômodos podem ser vistas usando como recurso uma sequência de fotografias ( 1 a a $)$ e trechos de entrevistas com o Sr. Laurentino Fernandes e Malaquias Batista, gravadas enquanto eles me guiavam nos cômodos da casa sede da Capitão-Mor. Na sala de estar ( foto 2) ficam as fotografias da família, diplomas, quadros e objetos feitos de couro de gado ou caprino, apoiados nos 
vários punhos para rede na parede. A porta de saída liga o quintal e um conjunto de quartos na parte exterior da casa.

\section{Foto 2: Objetos na sala de estar da casa sede da fazenda Capitão-Mor}

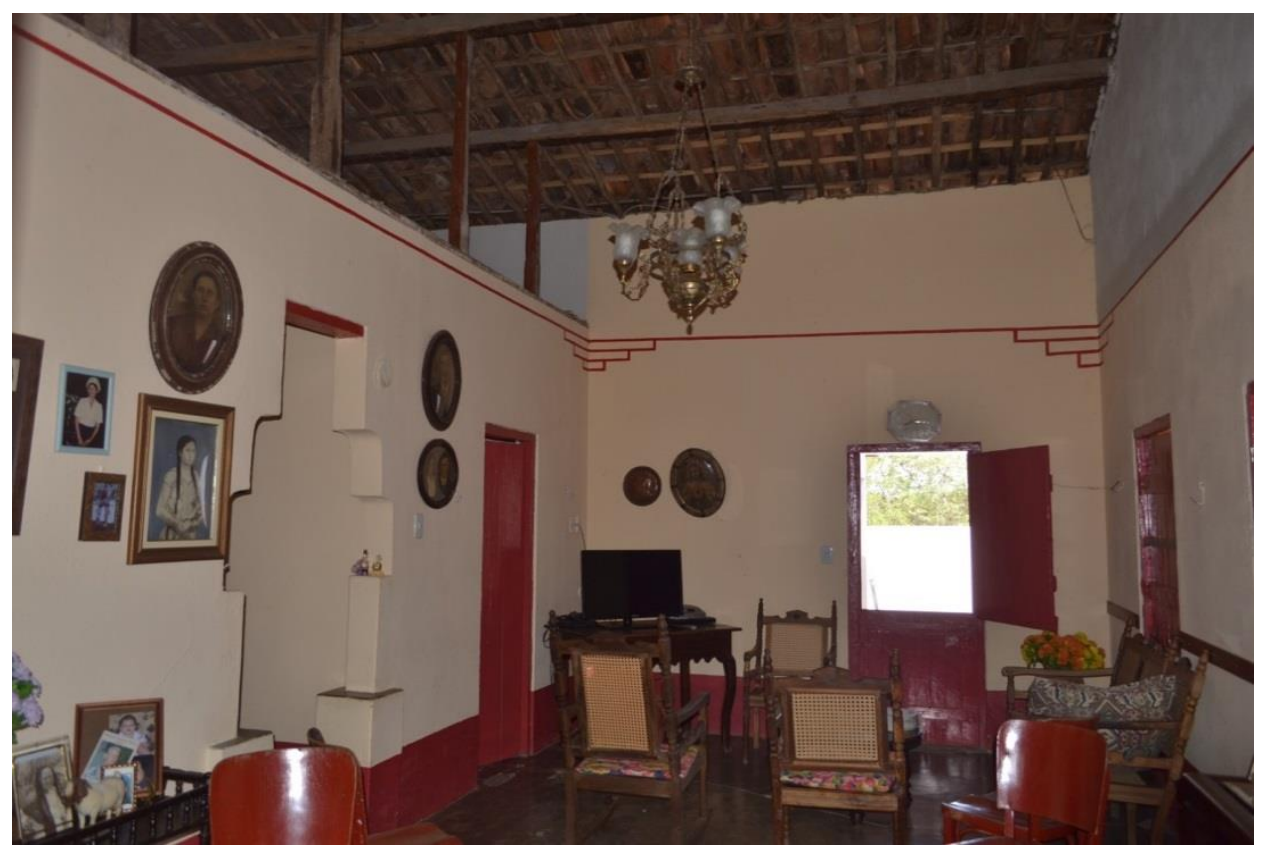

Registro feito por Valdênio Meneses (2015)

Uma das mais novas construções na propriedade Capitão-Mor é o museu "Major Sérgio Santana", concluído em 2007, e aberto à visitação desde 2014. Nos livros, esse espaço memorial é tido como um centro histórico e cultural para as novas gerações das famílias “bicentenárias dos descendentes do capitão João José” (BATISTA FILHO, 2014, P. 65). Feito a partir de reforma no prédio da antiga escola primária "particular" da fazenda que os filhos de Malaquias e Sinhá estudaram as primeiras séries do ensino fundamental, o museu abriga em seu acervo os objetos considerados relíquias da família, distribuídos em três salas 
Tabela 3. Acervo do museu Major Sérgio Santana na fazenda Capitão-Mor

\begin{tabular}{|c|c|}
\hline $\begin{array}{l}\text { SALA } 1- \\
\text { Fotografias } \\
\text { e cartas }\end{array}$ & $\begin{array}{l}\text { - Fotografias de bisnetos e tataranetos do Capitão João José da Silva de um tronco da família } \\
\text { Santana; } \\
\text { - Uma ordem do mérito, assinada pela matriarca Sebastiana Fernandes e por Malaquias Batista } \\
\text { Filho, que, em nome da família Fernandes, premiam José Fernandes Neto pelo Seminário de } \\
\text { Viabilização econômica, feito em Capitão-Mor e Pitombas, em } 17 \text { de janeiro de 2000. O texto } \\
\text { destaca "relevantes serviços de José Fernandes para viabilizar alternativas sócio-econômicas de } \\
\text { convivência com o ambiente geográfico e as tradições culturais do Cariri paraibano; } \\
\text { - Uma moldura com carta datilografada por Zezé Amaral, de um discurso feito em 20/01/2001, } \\
\text { em encontro na fazenda Pitombas. Na carta, Zezé coloca a seguinte passagem: "imaginem se } \\
\text { essas terras tivessem passado para pessoas que desconhecem o sacrifício de nossos ancestrais } \\
\text { para construí-las. Teriam usado máquinas e mãos criminosas para demolir toda uma história, } \\
\text { como tantas outras que não tiveram sorte e a dedicação de serem preservadas pelo amor e } \\
\text { dedicação dos Fernandes"; } \\
\text { - Uma moldura com um poema de Malaquias Batista Filho, chamado "Pesqueira ou a sereia da } \\
\text { saudade"; } \\
\text { - Um marcador de pluviometria de uma estação meteorológica do Cariri da Paraíba, entre os } \\
\text { anos de } 1970 \text { até } 1992 \text {; } \\
\text { - Um panfleto com a programação da Festa de Santa Clara de } 1991 \text {. }\end{array}$ \\
\hline $\begin{array}{c}\text { SALA } 2 \text { - } \\
\text { Objetos }\end{array}$ & $\begin{array}{l}\text { - Uma sela de montaria que pertenceu a Malaquias Batista; } \\
\text { - Um chapéu da marca "Prada" presente dos filhos para Malaquias Batista; } \\
\text { - Um baú encouraçado para guardar roupas que pertenceu a Sebastiana Fernandes; } \\
\text { - Material para costura, renda e renascença, doado pelos filhos de Quitéria de Souza Lima. }\end{array}$ \\
\hline $\begin{array}{l}\text { SALA 3 - } \\
\text { Ferramentas } \\
\quad \text { e armas }\end{array}$ & $\begin{array}{l}\text { - Espingardas utilizadas por Pedro de Souza Lima, durante a } 1^{\text {a }} \text { expedição à guerra de Canudos; } \\
\text { - Motor Slavia, utilizado para a produção de algodão; } \\
\text { - Telefone antigo utilizado na fazenda; } \\
\text { - Peças de tijolos que pertenceram à primeira casa do capitão João José, na fazenda Pitombas. } \\
\text { - Bolandeira de pedra usada para moer grãos }\end{array}$ \\
\hline
\end{tabular}

Outro fator de memória tão importante quanto a arquitetura ou a criação de um "museu-fazenda" são aqueles, por assim dizer, "naturais", como os caprinos do rebanho das fazendas e as pedras, árvores, riachos, dentre outros locais pertencentes às propriedades Pitombas, Santa Clara e Capitão-Mor, que marcam momentos na história da família Fernandes Batista. Há também projetos de conservação e jornadas de debates sobre convivência com as secas feito nas fazendas (MENESES, 2018).

\section{CONSIDERAÇÕES FINAIS}

Discutir sociologicamente, como as memórias da escolarização e das fazendas são narradas nos livros dos Fernandes Batista permite esclarecimentos sobre como é 
produzida, convertida e reconvertida, por "tortuosos" caminhos, a qualidade distinta de uma elite agrária e pecuarista. E, para guardar e moldar a energia sentimental desse "tempo social pretérito perfeito", as casas sede, os galpões, currais e celeiros, antes usados apenas para funções de trabalho ou de ensino dos filhos dos donos da fazenda, tornam-se locais de arquivos, locais de exposição e museus abertos à visitação. Não é coincidência cronológica que a iniciativa de construir arquivos e museus nas fazendas do Cariri paraibano e a própria publicação dos livros de memória tenham iniciado, em sua maior parte, entre as décadas de 1980 a 2000, período em que houve não apenas uma crise econômica - afinal, o algodão e a pecuária , sujeitos a um mercado e aos ciclos das secas, passaram por várias oscilações de preços desde o final do século XIX -, mas uma dissolução de uma ordem moral e social, um modo de vida em que o fazendeiro pecuarista tinha dominação legítima. Fundar lugares simbólicos de memória nas fazendas indica, portanto, uma luta de um grupo diante de um sentimento de perda de um passado ameaçado de ser diluído ou soterrado em mudanças sociais. "Se vivêssemos verdadeiramente as lembranças que eles [os locais de memória] envolvem, eles seriam inúteis" (NORA, 1993, p. 7).

Diante de "novos tempos", uma elite atrelada a um certo passado tenta transformar a sua herança econômica e principalmente simbólica. Com isso, podem ser feitas algumas considerações e propor agendas de pesquisa:

A) A "nostalgia" distinta, negação da decadência e a harmonia do passado da fazenda: se houve um "fim" das atividades econômicas que fizeram altivas as fazendas, então, é preciso revestir este espaço com outros fins: a fazenda tem intensificada a imagem de local de encontro, de exaltação da memória e da saudade do "passado ideal", "pretérito perfeito" sem conflitos de poder entre fazendeiros e moradores; uma estratégica salvaguarda contra qualquer questionamento de produtividade ou da finalidade social do espaço fundiário após o desmonte da relação e moradia. $\mathrm{O}$ afastamento de qualquer explicação das transformações na economia das fazendas como "decadência" ou "declínio" da imagem coletiva que os herdeiros fazem de si mesmos. As memórias dos Fernandes Batista falam em "fim dos ciclos" do algodão, caroá e um endividamento das fazendas para reafirmar um valor distinto: na visão da elite quando um "ciclo "acaba é um momentos fundamental para que seja mobilizado o esforço que os 
pais para formas os filhos doutores. Outro ponto é o ocultamento de narrativas que mencionavam as hierarquias, por vezes violentas, entre proprietários e moradorestrabalhadores da fazenda. Essa construção do passado da fazenda é criteriosamente selecionada sob uma lente bucólica, harmônico e idílica.

B) Regionalismo,, a pecuária caprina e o discurso da convivência com semiárido: já é registrado como a pecuária tem sido retomada em dimensões econômicas e simbólicas em diferentes regiões do semiárido nordestino ( NUNES, 2012, 2018). No caso da pecuária caprina - antes de baixo status e associada aos pobres - o caso dos Fernandes Batista mostra como uma elite tem investido em melhoramentos genéticos e um forte discurso regionalista. Esses movimentos parecem "enlaçar" estratégias memoriais e de investimento econômico junto a experimentos de convivência com as secas: assim a grande fazenda e vista, não como vetor de relações arcaicas de dominação, mas como exemplar de uma crença legitimada por um conjunto de teses, cartilhas e programas governamentais como um novo paradigma civilizador na visão sobre as secas no Nordeste( SILVA, 2008). Daí, ser necessário estabelecer uma agenda de pesquisa mais aprofundada sobre os Fernandes Batista e outras famílias da região do semiárido nordestino que tem investido em diferentes frentes: da memória ao criatório caprino nas suas fazendas.

\section{REFERÊNCIAS}

ABREU, Casimiro. Capítulos de História Colonial (1500-1800). 4 ed. Livraria Briguiet, [1907] 1954.

ALBUQUERQUE JR., Durval. A invenção do Nordeste e outras artes. 5 ed. São Paulo: Cortez, 2009.

ALBUQUERQUE JR. Durval. Nordestino de saia rodada e calcinha preta ou as novas faces do regionalismo e do machismo no Nordeste. In: QUEIROZ, A. (Org.) A reinvenção do Nordeste, V. 1, Sesc Ceará, 2010, p. 61-86.

AMARAL FRANÇA. Maria José. Retrato Escrito, V.II. Recife: CEPE, 2002.

AMARAL FRANÇA. Maria José. Retrato Escrito, V.III. Recife: CEPE, 2004.

AMARAL FRANÇA. Maria José. Um dia na vida de Mãe Sinhá In: BATISTA FILHO, M. (Org.) Mãe Sinhá: memórias e lições. Recife: Imprima, 2014. 
ARANHA,Gervácio. Campina Grande no espaço econômico Regional. Estrada de Ferro, tropeiros e empório comercial algodoeiro ( 1907 -1957). Campina Grande, UFPB,. Dissertação de mestrado em Sociologia Rural, 1991.

BATISTA FILHO, M. (Org.) Mãe Sinhá: memórias e lições. Recife: Imprima, 2014.

BATISTA, Francisco de Assis. Nas trilhas da resistência cotidiana: o protagonismo exercitado pelos camponeses no Cariri paraibano (1900-1950). Tese apresentada no Programa de Pós Graduação em Ciências Sociais (PPGCS), UFCG , Campina Grande, 2010

BOURDIEU, Pierre ; BOLTANSKI, Luc. SAINT MARTIN, Monique de. Les strategies de reconversion: les classes sociales et le système d'einsegnement. Social Science Information, 1973, p. 61-113

BOURDIEU, Pierre . Contradições da herança. In: NOGUEIRA, Maria Aparecida.; CATANI, Afrânio. ( Orgs.) Escritos de Educação, 9 ed., Rio de Janeiro, Vozes, 2014, p. $183-193$

BOURDIEU, Pierre. A ilusão biográfica. In : FERREIRA, Maria ; AMADO, J. (Orgs.) Usos e abusos da história oral, 8 ed., FGV, Rio de Janeiro, 2006, p. 183-193.

BRUNO, Regina. Agronegócio, Ruralismo e Relações de poder. Rio de Janeiro: Mauad X, Seropedica, RJ, 2009.

BUANAIN, Antonio; DEDECCA, Carlos. Pobreza rural e desenvolvimento no semiárido nordestino: resistência, reprodução e transformação. In: BUANAIN, Antonio; DEDECCA, Carclos. A nova cara da pobreza rural: desenvolvimento e questão regional. Brasília, IICA, 2013, p. 217-306.

CANÊDO, Leticia. La production genealogique et les modes de transmission d'um capital politique dans le Minas Gerais brésilien. Genesis, 31,1998, p. 4-28

CUNHA, Luis ; GOMES, Ramonildes . A trajetória da algaroba no semiárido nordestino: dilemas políticos e científicos. Raizes (UFPB), v. 33, 2012, p. 45-69,

DE OLIVEIRA, Ricardo Costa; GOULART, Mônica; VANALI, A. C; MONTEIRO, José Marciano. Família, parentesco, instituições e poder no Brasil: retomada e atualização de uma agenda de pesquisa. REVISTA BRASILEIRA DE SOCIOLOGIA, v. 5, 2017, p. 165-198,

DUQUÉ, Ghislaine; Estrutura fundiária e pequena produção : um estudo de caso no Cariri Paraibano. Revista Raízes, Campina Grande, Ano IV, n 4-5, jan-dez, 1985, p.168-196. 
FAVARETO, Arilson.; ABRAMOVAY, Ricardo; OLIVEIRA, M.; DINIZ, J.F; SAES, B. Desenvolvimento territorial em uma região do semiárido brasileiro do Nordeste Brasileiro- para além das transferências de renda. Documento de trabalho $n^{\circ} 83$. Programa Dinâmicas Territoriales Rurales. Rimisp- Centro Latinoamericano para o desarollo rural, Santiago, Chile, 2011, p. 1-29.

FERNANDES BATISTA, L.; FERNANDES BATISTA, I.; BATISTA FILHO, M. (Orgs.) Papai: histórias \& estórias: livro comemorativo do centenário de nascimento de Malaquias Batista Feitosa (1905-2005). Recife, 2005.

FERNANDES NETO, J. O empreendedor. In: FERNANDES BATISTA, L.; FERNANDES BATISTA, I.; BATISTA FILHO, M (Orgs.). Papai: histórias \& estórias: livro comemorativo do centenário de nascimento de Malaquias Batista Feitosa (19052005). Recife, 2005.

FRANÇA, M.J. Retrato Escrito, V.1. Recife: CEPE, 1993.

GÁRCIA JR., Afrânio. O sul a caminho do roçado: estratégias de reprodução camponesa e transformação social. São Paulo, Marco Zero, 1989

GARCIA JR., Afrânio. Os vice-reis do Norte: reconversão de elites agrárias e a Revolução de 1930 (1920-1964). Revista de Ciências Sociais, v. 38 (02), 2007,

HALBWACHS, Maurice. A memória coletiva. São Paulo, Vértice. 1990

HEREDIA, Beatriz. A morada da vida. Rio de Janeiro. Paz e Terra 1970

LE WITA, Beatrix. Memoire, l’avenir du présent. Terrain, 4, 1985.

LEAL, Natalia. Simei. Nome aos bois: zebus e zebuzeiros em uma pecuária brasileira de elite. São Paulo, Hucitec, Anpocs, 2016.

LEWIN, Linda. Política e Parentela na Paraíba. Um estudo de caso da oligarquia de base familiar. Rio de Janeiro: Record,1993, p.131-163.

MAIA, Kaliane.; CUNHA, Luis Henrique. Narrativas sobre a grande propriedade pecuária do sertão nordestino: território da pecuária, do latifúndio e das oligarquias. Revista Raízes, UFCG, V.35, N.2, Jul-Dez, 2015, p. 84-100.

MALVEZZI, Roberto. Semi-árido: uma visão holística. Brasília, DF: Confea. 2007.

MARQUES, A. C. Intrigas e questões: vingança de família e tramas sociais no Sertão de Pernambuco. Rio de janeiro: Relume Dumará, UFRJ, NuaP, 2002.

MENESES, Valdênio. Saudade e rusticidade: reconversões sociais e convivência com as secas entre elites pecuaristas do Cariri Paraibano. Tese apresentada no Programa de Pós- Graduação de Ciências Sociais em Desenvolvimento Agricultura e Sociedade 
(CPDA/UFRRJ), Rio de Janeiro, 2018.

MENEZES, Marilda. Migrações: Uma experiência histórica do campesinato no Nordeste In: GODOI, E.; MENEZES, M.; MARIN, R. (Orgs). Diversidade do campesinato: expressões e categorias, v.2. São Paulo, UNESP, NEAD, 2009, p. 269-289.

MONTEIRO, José Marciano. A política como negócio de família: para uma sociologia das elites e do poder político familiar. São Paulo, Liber Ars, 2016.

MOREIRA, Emilia.; TARGINO, Ivan. Capítulos de Geografia Agrária. João Pessoa: Editora Universitária da Paraíba, 1997.

MOREIRA, Gislaine. A nova cara do sertão: provocações sobre juventude e cultura contemporânea In. FREIRE, A (Org.) Culturas dos Sertões. Salvador: Edufba. 2014, p. 227-244.

NORA, Pierre. Entre história e memória: a problemática dos lugares. Proj. História, São Paulo (10), dez, 1993. p. 73-87.

NUNES FILHO, P. Guerreiro Togado: Fatos históricos de Alagoa de Monteiro. Recife: Ed. Universitária - UFPE. 1997

NUNES, Aldo Manuel. Currais, cangalhas e vapores: dinâmicas de fronteira e conformação das estruturas social e fundiária nos sertões da Borborema (17801920). Tese de doutorado apresentada no Programa de Pós-Graduação de Ciências Sociais (PPGCS) da Universidade Federal de Campina Grande (UFCG), 2016.

NUNES, Aldo Manuel. A (re)pecuarização do semiárido nordestino: manifestações culturais e reabilitação simbólica do rural no Pajeú (PE). Raizes - Revista de Ciências Sociais e Econômicas, v. 38, n 01, 2018, p. 129-144.

PINÇON, Michel; PINÇON-CHARLOT, Michel. A infância dos chefes - a socialização dos herdeiros ricos na França. In: ALMEIDA, Alice; NOGUEIRA, Marialice ( Orgs). A escolarização das elites: um panorama internacional de pesquisa. Petrópolis, Vozes, 2002, p. 11-29.

PINÇON, Michel; PINÇON-CHARLOT, Monique. Sociologia da Alta Burguesia. Sociologias. Porto Alegre: Ano 9, n.18, jul/dez 2007, p. 22-37.

RIBEIRO, Eduardo. Agregados e fazendas no nordeste de Minas Gerais. Estudos Sociedade e Agricultura, Rio de Janeiro, 2010, v.18, n.2, p. 393-433

SAINT MARTIN, Monique. Reconversões e reestruturações das elites: o caso da aristocracia em França. Análise Social, v. XXX ( 134), 1995, p. 1023- 1039 
N E P Revista NEP - Núcleo de Estudos Paranaenses, Curitiba, v. 5, n. 2, dez. 2019

SAINT-MARTIN, Monique. Modos de educação dos jovens aristocratas e suas transformações. In: ALMEIDA, A.M; NOGUEIRA, M.A (Orgs) A escolarização das elites: um panorama internacional de pesquisa, Petrópolis, Vozes, 2002, p.29-49

SIGAUD, Lygia. Armadilhas da honra e do perdão: usos sociais do direito na mata pernambucana. Mana, 10, V.1 2004.

SILVA, Mirian da. Reforma agrária de mercado ou atualização do clientelismo? 0 Programa Nacional de Crédito Fundiário e o assentamento de famílias sem terra no Cariri Ocidental Paraibano. ' Dissertação de mestrado apresentada no Programa de Pós Graduação em Ciências Sociais (PPGCS), UFCG, Campina Grande, 2012

SILVA, Roberto Marinho da. Entre o combate à seca e a convivência com o semi árido: transição paradigmática e sustentabilidade do desenvolvimento. Fortaleza: BNB, 2008 .

Recebido em: 14 out. 2019

Aceito em: 26 nov. 2019 